\title{
Economics of open field tomato production in Punjab
}

\author{
Qamar Ali ${ }^{1,2, *}$, Muhammad Tariq Iqbal Khan ${ }^{3}$, Muhammad Ashfaq ${ }^{1}$ \\ 1 Institute of Agricultural and Resource Economics, University of Agriculture, Faisalabad-38000, Pakistan \\ ${ }^{2}$ Department of Economics, Virtual University of Pakistan, Faisalabad Campus-38000, Pakistan \\ ${ }^{3}$ Department of Economics, Government Postgraduate College, Jaranwala-35200, Punjab, Pakistan
}

\section{A R T I C L E IN F O}

\section{Article history:}

Received 20 November 2016

Received in revised form

1 February 2017

Accepted 1 February 2017

\section{Keywords:}

Benefit cost ratio

Cobb-Douglas

Gross income

Net income

Vegetables

\begin{abstract}
A B S T R A C T
Food security becomes a global issue, especially in developing countries. Approximately $19.8 \%$ of GDP comes from agriculture in Pakistan. Increase in vegetable production is necessary for food security, eliminate poverty and increase in employment opportunities. There is no sufficient literature about the regression analysis in open field tomato production. Present study aims for the estimation of per acre costs, returns and determinants of revenue in open field tomato production in Punjab, Pakistan. Primary data were collected from 70 farmers with stratified random sampling. Cobb-Douglas model was applied for regression analysis. Total production cost was higher for medium farmers (Rs. 177,288.36) followed by small (Rs. 171,872.71) and large (Rs. 171,750.74) farmers. Total production was more for medium farmers $\left(14,261.58 \mathrm{~kg}\right.$ acre $\left.^{-1}\right)$ while small farmers earned higher revenue (Rs. $484,545.90$ acre $^{-1}$ ) and price (Rs. $34.86 \mathrm{~kg}^{-1}$ ). According to BCR, small farmer received Rs. 2.83 by investing rupee one in this business as compared to medium (Rs. 2.59) and large (Rs. 2.49) farmers. Education, extension agent contacts, experience, seed quantity, chemical applications and marketing cost had a positive and significant impact on revenue. $R^{2}(0.856)$ and $f$-value (34.961) reflects the goodness of the regression model. Results have a support from previous studies, but it is a new addition in Pakistan. Price fluctuation, less extension services and disease attack were the main problems. The government should eliminate these problems. The government should improve the technical knowledge of farmers. Government should ensure the purity of agricultural inputs such as fertilizers, seed and chemicals.
\end{abstract}

(C) 2017 The Authors. Published by IASE. This is an open access article under the CC BY-NC-ND license (http://creativecommons.org/licenses/by-nc-nd/4.0/).

\section{Introduction}

The production of vegetables has an important place in agriculture with respect to economic return (Zaman et al., 2010). There exists an increasing trend in area and production of vegetable in the world because vegetable yield was 5 to 10 times more as compared to cereals and millets. Vegetable shows fast growth with less cropping duration (Shende and Meshram, 2015). Vegetable production is also important for food security and reduction in poverty (Ishaq et al., 2003). The achievement of WHO recommended per capita vegetable consumption (73 $\mathrm{kg}$ per annum) is a primary challenge in agriculture because vegetable consumption per capita was less

\footnotetext{
* Corresponding Author.

Email Address: qamarali2402@gmail.com (Q. Ali)

https://doi.org/10.21833/ijaas.2017.02.014

2313-626X/C 2017 The Authors. Published by IASE.

This is an open access article under the CC BY-NC-ND license

(http://creativecommons.org/licenses/by-nc-nd/4.0/)
}

(35.6 kg per annum) in Pakistan (Abedullah et al., 2006).

Tomato (Solanum lycopersicum) is a popular, nutrition rich and versatile fruit/vegetable which is widely grown in the world (Usman and Bakari, 2013; Baksh et al., 2015). Tomato is a major commercial vegetable and can increase the earnings of rural people with the provision of employment and improvement in living standard (Wachira et al., 2014). It is considered as a protective food due to their nutritional composition such as the presence of ascorbic acid, lycopene, vitamin $\mathrm{E}$ and phenol compounds (Sepat et al., 2013). It is used in various forms such as raw salad, cooked, sauce, jam, ketchup, pickles, soup, jelly and other related forms (Mohiuddin et al., 2007).

In Pakistan, tomato production area during Kharif (autumn) season was 17,336 ha in 2013-14 and 17,007 ha in 2012-13. Total tomato production in Kharif season was 145,872 tonnes in 2013-14 and 142,604 tonnes in 2012-13. Tomato yield in Kharif season was 8,414.4 kg per ha in 2013-14 and 8,385.0 
kg per ha in 2012-13. In Pakistan, tomato production area during Rabi (winter) season was 45,594 ha in 2013-14 and 41,189 ha in 2012-13. Total tomato production in Rabi season was 453,716 tonnes in 2013-14 and 431,448 tonnes in 2012-13. Tomato yield in Rabi season was 9,951.4 kg per ha in 201314 and 10,474.8 kg per ha in 2012-13. In Punjab, tomato area during Rabi season was 7,797 ha in 2013-14 and 6,556 ha in 2012-13. Total tomato production in Rabi season was 100,078 tonnes in 2013-14 and 86,269 tonnes in 2012-13. Tomato yield in Rabi season was $12,835.45 \mathrm{~kg}$ per ha in 2013-14 and 12,158.79 kg per ha in 2012-13.

Allah Almighty gives a suitable climate to Pakistan for vegetable production in different zones. Vegetables shows high demand and their prices were more at the start and end of the season due to the vegetable shortage. There exist some cross country studies about the economic analysis of tomato production (Wachira et al., 2014; Baksh et al., 2015; Noonari et al., 2015; Shende and Meshram, 2015) but according to available literature, no study explored the economics of open filed tomato production in Punjab.

Noonari et al. (2015) conducted the economic analysis of tomato production with a sample size of 60 respondents in Naushahro Feroze, Sindh, Pakistan in 2013. Results showed that maximum $36.66 \%$ farmers have 8 years of education. On average, total fixed cost was (Rs 33,187.00 ha-1). On average, total production cost was Rs. 87,617.13 ha-1 including labour cost (Rs 19,780.75 ha-1) and marketing cost (Rs. 30,457.65 ha-1. Average physical productivity was 186.00 pounds per acre. Average revenue was Rs.158,750.00 per acre with net income (Rs. 71,133.00 per acre) and input output ratio (1:1.81). It shows the return was Rs. 1.81 by investing Rs.1 as cost of production. The production was less due to poor soil quality, shortage of canal water, attack of insect pest and poor extension services. They pointed out the potential of increase in production by using modern technology.

To increase the area under vegetables, it is necessary to aware the farmers about its cost and return. Therefore, the present study aims for the estimation of total production cost, total revenue, gross margin, net income, benefit-cost ratio and determinant of revenue in open field tomato production.

\section{Materials and methods}

This study was based on primary data which were collected from districts Faisalabad and Toba Tek Singh in 2014. The appropriate sample size for the large population size was 60 in order to get better results (Poate and Daplyn, 1993; Mari, 2009). Therefore, total 70 open field tomato growers were personally interviewed by using a stratified random sampling method. Stratifies random sampling method is useful when the total population is divided into sub-groups such as small, medium and large farmers for present research. A sample is taken from each sub-group on a random basis (Teddlie and $\mathrm{Yu}$, 2007). A farmer with less than 12.5 acres operational land is called a small farmer while a farmer with more than 12.5 acres and less than 25 acres is a called medium farmer, and a farmer with more than 25 acres is called a large farmer (Hassan et al., 2005).

\subsection{One-way analysis of variance (ANOVA)}

ANOVA is used to explore the difference in the mean value of various sub-groups (Ostertagová and Ostertag, 2013). Null and alternative hypothesis are expressed as:

Null hypothesis $\mathrm{H}_{0}: \quad \mu_{1}=\mu_{2}=\mu_{3}$ Alternative hypothesis $\mathrm{H}_{1}: \mu_{1} \neq \mu_{2} \neq \mu_{3}$

Null hypothesis explored the equality of mean values for all sub groups while the alternative hypothesis reflects the difference in mean values for all sub-groups.

\subsection{Estimation of costs and returns}

Total revenue and total cost were estimated for open field tomato production. It has various variable costs such as cost of land preparation, seed and seedling transplantation, earthling up, fertilization, hoeing, pesticides, irrigation, picking and marketing. Fixed cost includes interest payment on variable cost, administration charges, land rent and abyana (canal water charges). Mwangi (2012) also calculated interest on the total variable cost and current study used 8\% rate of interest. Land rent was calculated for seven months. Abyana is a component of fixed cost (Noonari et al., 2015). Gross margin (GM), net income (NI) and Benefit-cost ratio were calculated by using formulas (Usman and Ashfaq, 2013) expressed as:

$\mathrm{GM}=\mathrm{TR}-\mathrm{VC}$

where, GM denotes gross margin, TR shows total revenue and VC shows variable cost.

$\mathrm{NI}=\mathrm{TR}-\mathrm{TC}$

where, NI represents net Income, TR represents total revenue and TC represents total Cost.

Benefit Cost Ratio (BCR) depicts the amount of money received due to the investment of one rupee as total cost (Eq. 3):

$\mathrm{BCR}=\frac{\mathrm{TR}}{\mathrm{TC}}$

\subsection{Econometric model specification}

Easy computation and interpretation are advantages for the use of Cobb-Douglas model (Heady and Dillon, 1961; Usman and Ashfaq, 2013). Cobb-Douglas model was transformed into 
logarithmic form by Beattie and Taylor (1985) due to the easiness in coefficient estimation in linear form which is expressed as (Eq. 4):

$\ln Y=\ln a+\beta_{1} \ln X_{1}+\beta_{2} \ln X_{2}+\beta_{3} \ln X_{3}+\beta_{4} \ln X_{4}+$

$\beta_{5} \ln X_{5}+\beta_{6} \ln X_{6}+\beta_{7} \ln X_{7}+\beta_{8} \ln X_{8}+\beta_{9} \ln X_{9}+\beta_{10} \ln X_{10}+$

$\ln U_{\mathrm{i}}$

where,

$\mathrm{Y}=\quad$ Average revenue (Rs.)

$\mathrm{X}_{1}=\quad$ Education (Years)

$\mathrm{X}_{2}=\quad$ Contacts with extension agents (No)

$\mathrm{X}_{3}=\quad$ Tomato experience (Years)

$\mathrm{X}_{4}=\quad$ Land preparation cost (Rs.)

$\mathrm{X}_{5}=\quad$ Seed (Kg.)

$\mathrm{X}_{6}=\quad$ NPK cost (Rs.)

$\mathrm{X}_{7}=\quad$ Chemical applications (No.)

$\mathrm{X}_{8}=\quad$ Irrigation cost (Rs.)

$\mathrm{X}_{9}=\quad$ Labour cost (Rs.)

$\mathrm{X}_{10}=\quad$ Marketing cost (Rs.)

ln $=\quad$ Natural logarithm

$\mathrm{a}=$ constant

$\mathrm{Ui}=$ Error term which indicates the effect of unexplained factors $\beta_{1} \ldots . . . \beta_{12}$, are coefficients of estimates.

\section{Results and discussion}

Table 1 demonstrates mean and ANOVA of socioeconomic variables of open field tomato growers. On average, age was higher for large farmers (45.48 years) but difference in the mean value was insignificant. Education was more for large farmers (8.61 years) and the difference in mean value of education was insignificant. There is a significant difference between average family sizes for all subgroups. The family size was more for medium farmers. Average operational land holding was higher for large farmers (39.72 acres) and the difference in average operational land holding among all sub-groups was highly significant. Contact with extension staff was more for large farmers and the mean difference was also significant. Both open field tomato growing experience (5.87 years) and area under open field tomato ( 4.24 acre) was more for large farmers and shows a significant mean difference between three sub-groups.

Table 1: Mean and ANOVA of socio-economic variables

\begin{tabular}{cccccc}
\hline Particulars & \multicolumn{3}{c}{ Farm Size Category } & \multicolumn{2}{c}{ One-way ANOVA } \\
\cline { 2 - 5 } & Small & Medium & Large & F-value & Sig. \\
\hline Age (years) & 37.54 & 43.63 & 45.48 & 2.294 & 0.109 \\
Education (years) & 8.25 & 8.79 & 8.61 & 0.125 & 0.883 \\
Family Size & 6.43 & 8.95 & 6.57 & $5.737^{*}$ & 0.005 \\
Total operational holding (acres) & 7.40 & 16.39 & 39.72 & $49.686^{*}$ & 0.000 \\
Contacts with extension agents & 3.32 & 3.37 & 4.70 & $4.769^{* *}$ & 0.012 \\
Open field tomato experience (years) & 3.32 & 5.00 & 5.87 & $2.933^{* * *}$ & 0.060 \\
Open field tomato area (acres) & 1.20 & 2.97 & 4.24 & $13.145^{*}$ & 0.000 \\
\hline *significant at 1\%, ${ }^{* *}$ significant at $5 \%,{ }^{* * *}$ significant at 10\% &
\end{tabular}

Table 2 reveals average variable cost in open field tomato production on a per acre basis. On average, a large farmer spends more money on land preparation (Rs. 12,487.64), fertilization (Rs. 22,732.61), hoeing (Rs. 3,302.05), irrigation (Rs. 10,985.37) and marketing (Rs. 44,983.65). On average, medium farmer spends more financial resources on seed (Rs. 8,476.32), seedling transplantation (Rs. 2,098.55) and pesticide and weedicide (Rs. 17,053.08). On average, the expenditures of small farmer were more for earthing up (Rs. 1,381.01) and picking (Rs. 31,169.53). Total variable cost was higher for medium farmer (Rs. $150,901.72$ ) followed by small (Rs. 147,267.26) and large farmers (Rs. 146,196.22). Land rent (Rs. 20,065.79) and interest on variable cost (Rs. 1,724.59), administrative cost (Rs. 4,527.05) and abyana or canal water charges (Rs. 69.21) was more for medium farmer. Total production cost was higher for medium farmers (Rs. 177,288.36). Baksh et al. (2015) estimated total variable cost (US \$3,491 ha${ }^{1}$ ), gross return (US $\$ 17,228 \mathrm{ha}^{-1}$ ), gross margin $\left(13,737 \mathrm{ha}^{-1}\right)$ and BCR (4.63) in tomato production in Bangladesh.

Table 3 reveals higher level of production for medium farmers $\left(14,261.58 \mathrm{~kg} \mathrm{acre}^{-1}\right)$ while small farmers received a higher price (Rs. $34.86 \mathrm{~kg}^{-1}$ ) followed by medium (Rs. $32.18 \mathrm{~kg}^{-1}$ ) and large farmer (Rs. $30.87 \mathrm{~kg}^{-1}$ ). The difference in the average price received by different sub group was found insignificant.

Per acre tomato production was $10,000 \mathrm{~kg}$ in Bangladesh as reported by Zaman et al. (2010) and it was less than the findings of the current study. Yield of tomato in Bangladesh was 34.48 ton ha-1 or $13953.58 \mathrm{~kg}$ acre $^{-1}$ (Mohiuddin et al., 2007) which was very close to present findings. Total revenue was higher for small farmers (Rs. 484,545.90 $\mathrm{acre}^{-1}$ ). Both GM (Rs. 339,278.64 acre $^{-1}$ ) and NI (Rs. $314,673.19$ acre $^{-1}$ ) were also higher for the small farmer. BCR was more in case of small farmers (2.83) followed by medium (2.59) and large (2.49) farmers. It depicts that small farmer received a return of Rs. 2.83 by investing rupee one in open field tomato production.

BCR was 1.85 in tomato production as estimated by Shende and Meshram (2015) with a total cost (76417 Indian rupees ha-1) and net return (65139.23 Indian rupees ha-1). BCR was 1.94 in the same crop as found by Maniriho and Bizoza (2013). BCR in tomato production in Bangladesh was 1.7 with a total cost $(66,900 \mathrm{Tk}$.) and total return $(120,000 \mathrm{Tk}$.) as reported by Zaman et al. (2010). 
Table 2: Average input costs acre-1 (Rs.)

\begin{tabular}{cccc}
\hline \multirow{2}{*}{ Production Practices } & \multicolumn{3}{c}{ Farm Size Category } \\
\cline { 2 - 4 } & Small & Medium & Large \\
\hline Land Preparation & 11456.21 & 12089.34 & 12487.64 \\
Seed & 6615.71 & 8476.32 & 6791.30 \\
Seedling Transplantation & 2057.91 & 2098.55 & 2058.88 \\
Fertilization & 22548.21 & 23084.21 & 22732.61 \\
Hoeing & 2349.17 & 2553.17 & 3302.05 \\
Earthing up & 1381.01 & 1189.68 & 1075.63 \\
Pesticide + Weedicide & 15994.39 & 17053.08 & 15572.38 \\
Irrigation & 8733.69 & 9739.25 & 10985.37 \\
Picking & 31169.53 & 30091.41 & 26206.71 \\
Marketing & 44961.43 & 44526.71 & 44983.65 \\
Total Variable Cost & 147267.26 & 150901.72 & 146196.22 \\
Interest on variable cost & $(0.147)^{*}$ & $(0.151)^{*}$ & $(0.146)^{*}$ \\
Land Rent (Seven Months) & 1683.05 & 1724.59 & 1670.81 \\
Abyana & 4418.02 & 4527.05 & 4385.89 \\
Total Cost & 18437.50 & 20065.79 & 19434.78 \\
& 66.88 & 69.21 & 63.04 \\
Administrative cost (@ 3\% of variable cost) & 171872.71 & 177288.36 & 171750.74 \\
& $(0.172)^{*}$ & $(0.177)^{*}$ & $(0.172)^{*}$ \\
\hline
\end{tabular}

Table 3: Economic analysis

\begin{tabular}{cccc}
\hline \multirow{2}{*}{ Indicator/Unit } & \multicolumn{3}{c}{ Farm Size Category } \\
\cline { 2 - 4 } & Small & Medium & Large \\
\hline Production (Kg) & 13957.14 & 14261.58 & 13869.57 \\
Average Price (Rs. Kg-1) & 34.86 & 32.18 & 30.87 \\
Average Cost (Rs. Kg-1) & 12.31 & 12.43 & 12.38 \\
Total Revenue (Rs.) & 484545.90 & 458937.64 & 428153.63 \\
& $(0.485)^{*}$ & $(0.458)^{*}$ & $(0.428)^{*}$ \\
Gross Margin (Rs.) & 339278.64 & 308035.92 & 281957.41 \\
& $(0.339)^{*}$ & $(0.308)^{*}$ & $(0.282)^{*}$ \\
Net Income (Rs.) & 314673.19 & 281649.28 & 256402.89 \\
& $(0.315)^{*}$ & $(0.282)^{*}$ & $(0.256)^{*}$ \\
BCR & 2.83 & 2.59 & 2.49 \\
\hline
\end{tabular}

Table 4 describes the results of Cobb-Douglass production function. The estimated model was good on the basis of $R^{2}(0.856)$, adjusted $R^{2}(0.829)$ and $f$ statistics (34.961). It describes that the proposed production model explained $85.6 \%$ variation in revenue due to variations in the explanatory variables. The impact of education was positive (0.09) and significant which was in line with Ibekwe and Adesope (2010) and Mohammed (2015). It shows a $0.09 \%$ increase in revenue as a result of $1 \%$ increase in schooling years. The coefficient of experience was significant and positive (0.16) with a support from Ibekwe and Adesope (2010). The regression coefficient was positive (0.05) and significant for seed quantity. Coefficient of seed was also positive as reported by Mohiuddin et al. (2007). The coefficient was positive $(0.05)$ and significant for chemical application. Generally insect pest attack was more on vegetables and the quick chemical application is necessary in case of vegetable production. Respondents also told about the common disease attack in vegetables. The coefficient of irrigation cost was negative $(-0.05)$ and significant. The coefficient of irrigation was in line with the findings of Mohiuddin et al. (2007) and Akter et al. (2011).

\section{Conclusions}

Open field tomato production is a profitable business and it was in line with the finding of Mohiuddin et al. (2007), Zaman et al. (2010), Usman and Bakari (2013) and Noonari et al. (2015). Total cost of production in open field tomato was more (Rs. 177,288.36) for medium farmers and total production $(14,261.58 \mathrm{~kg})$ was also higher for medium farmers. Small farmers received a higher price (Rs. 34.86 per kg), revenue (Rs. 484,545.90 per acre), gross margin (Rs. 339,278.64 per acre) and net income (Rs. 314,673.19) than others. BCR was also more for small farmers (2.83) followed by medium (2.59) and large (2.49) farmers. Positive and significant impact on revenue was observed in case of education, contacts with extension agents, open field tomato growing experience, seed quantity, chemical applications and marketing cost. The regression model was good according to $R^{2}(0.856)$ and f-value (34.961).

Price fluctuations and disease attack are major hurdles in open field tomato production as told by respondents. Due to this, farmers prefer the production of staple food crop in Rabi season such as wheat due to attractive support price by the government. Respondents pointed out the lack of guidance by extension staff. It is required to increase the visits and guidance of extension agents about the use of inputs especially fertilizer, water and pesticides. Education and technical knowledge is also helpful to the progress of agriculture sector and government should improve the technical knowledge of farmers by establishing farmer field schools. Impurity in agricultural inputs is a problem in agriculture. Government should take strict action 
against the selling of impure inputs such as chemical

sprays and fertilizers.

Table 4: Regression results of Cobb-Douglass production function

\begin{tabular}{ccccc}
\hline Variable & Unit & Coefficient & $t$-value & $p$-value \\
\hline Constant & & $11.46^{*}$ & 12.49 & 0.000 \\
ln-education & Years & $0.09^{*}$ & 3.05 & 0.003 \\
In-contacts with extension agents & No. & $0.11^{* *}$ & 2.25 & 0.028 \\
In-tomato growing experience & Years & $0.16^{*}$ & 3.50 & 0.001 \\
ln-land preparation cost & Rs. & -0.01 & -0.14 & 0.891 \\
ln-seed quantity & Kg & $0.05^{* * *}$ & 1.92 & 0.060 \\
ln-NPK cost & Rs. & -0.01 & -0.32 & 0.747 \\
ln-chemical applications & No. & $0.05^{* *}$ & 2.24 & 0.029 \\
ln-irrigation cost & Rs. & $-0.05^{* * *}$ & -1.81 & 0.075 \\
ln-labour cost & Rs. & -0.04 & -1.08 & 0.283 \\
ln-marketing cost & Rs. & $0.20^{*}$ & 3.23 & 0.002 \\
\hline $\mathrm{R}^{2}=0.856 ;$ Adjusted-R ${ }^{2}=0.831 ;$ F-ratio $=34.961$ \\
\hline
\end{tabular}

\section{References}

Abedullah, Bakhsh K, and Ahmad B (2006). Technical efficiency and its determinants in potato production, evidence from Punjab, Pakistan. The Lahore Journal of Economics, 11(2): 122.

Akter S, Islam MS, and Rahman MS (2011). An economic analysis of winter vegetables production in some selected areas of Narsingdi district. Journal of Bangladesh Agriculture University, 9(2): 241-246.

Baksh ME, Rossi F, Krupnik TJ, Talukder ASMH, and McDonald A (2015). How much can smallholders in Bangladesh benefit from summer tomato cultivation? An applied agro-economic analysis of on farm data. SAARC Journal of Agriculture, 13(2): 80-93.

Beattie BR and Taylor CR (1985). The economics of production. Wiley, New York, USA.

Hassan S, Tabasam N, and Iqbal J (2005). An economic analysis of wheat farming in the mixed farming zone of Punjab Province, Pakistan. Journal of Agriculture \& Social Sciences, 1(2): 167171.

Heady EO and Dillon J (1961). Agricultural production functions. Iowa State University Press, Ames, USA.

Ibekwe UC and Adesope OM (2010). Analysis of dry season vegetable production in Owerri West local government area of Imo State, Nigeria. Journal of Development and Agricultural Economics, 2(6): 245-249.

Ishaq M, Sadiq G, and Saddozai SH (2003). An estimation of cost and profit functions for off season cucumber produce in district Nowshera. Sarhad Journal of Agriculture, 19(1): 155161.

Maniriho A and Bizoza AR (2013). Financial benefit-cost analysis of agricultural production in Musanze district, Rwanda. Academia Arena, 5(12): 30-39.

Mari FM (2009). Structure and efficiency analysis of vegetable production and marketing in Sindh, Pakistan. Ph.D. Dissertation, Sindh Agriculture Univversity, Tando Jam, Pakistan.

Mohammed B (2015). Analysis of resource use efficiency and profitability in chilli pepper (Capsicum Frutescens) production and its contribution to household farm income in Kaduna state. M.Sc. Thesis, Ahmadu Bello University, Zaria, Nigeria.
Mohiuddin M, Uddin MS, Rashid MH, Hossain KMF, and Matin MA (2007). Adoption and profitability of improved tomato variety in the Chittagong region of Bangladesh. Journal of Soil and Nature, 1(3): 52-58.

Mwangi WJ (2012). Comparative analysis of greenhouse versus open-field small scale tomato production in Nakuru-North district, Kenya. M.Sc. Thesis, Egerton University, Njoro, Kenya.

Noonari S, Mmemon IN, Arain MU, Sidhu MY, Mirani AA, Khajjak AK, Sial SA, Jamali R, Jamali RH, and Jamro AH (2015). Comparative economic analysis of hybrid tomato $\mathrm{v} / \mathrm{s}$ conventional tomato production in district Tando Allahyar Sindh, Pakistan. Food Science and Quality Management, 40: 114.

Ostertagová E and Ostertag O (2013). Methodology and application of one-way ANOVA. American Journal of Mechanical Engineering, 1(7): 256-261.

Poate CD and Daplyn PF (1993). Data for agrarian development. Cambridge University Press, Cambridge, UK.

Sepat NK, Sepat SR, Sepat S, and Kumar A (2013). Energy use efficiency and cost analysis of tomato under greenhouse and open field production system at Nubra valley of Jammu and Kashmir. International Journal of Environmental Sciences, 3(4): 1233-1241.

Shende NV and Meshram RR (2015). Cost benefit analysis and marketing of tomato. American International Journal of Research in Formal, Applied \& Natural Sciences, 1(11): 46-54.

Teddlie C and Yu F (2007). Mixed methods sampling: A typology with examples. Journal of Mixed Methods Research, 1(1): 77100.

Usman J and Bakari UM (2013). Profitability of small scale dry season tomato (Lycopersicon esculentum Mill.) production in Adamawa state, Nigeria. ARPN Journal of Science and Technology, 3(6): 604-610.

Usman M, and Ashfaq M (2013). Economic analysis of gladiolus (Gladiolus Hortulanus) production in Punjab, Pakistan. Journal of Agriculture Research, 51(3): 317-326.

Wachira JM, Mshenga PM, and Saidi M (2014). Comparison of the profitability of small-scale greenhouse and open-field tomato production systems in Nakuru-North district, Kenya. Asian Journal of Agricultural Sciences, 6(2): 54-61.

Zaman M, Hemel R, and Ferdous T (2010). Comparative profitability of winter vegetables in a selected area of Dhaka district. ASA University Review, 4(1): 217-223. 